\title{
PENGARUH KEPUASAN KERJA DAN BUDAYA ORGANISASI TERHADAP KOMITMEN ORGANISASI KARYAWAN PERUSAHAAN SWASTA DI TANJUNG PANDAN
}

\author{
Laurence Valencia Suyanto dan Mei Ie \\ Program Studi Manajemen Fakultas Ekonomi Universitas Tarumanagara, Jakarta \\ E-mail: laurence.115170300@stu.untar.ac.id; meii@fe.untar.ac.id
}

\begin{abstract}
The purpose of this study was to examine the effect of job satisfaction and organizational culture on employee organizational commitment. Respondents in this study consisted of 57 employees from 4 private companies in Tanjung Pandan, in which the company name is CV Mitra Sumber Mandiri, CV Laju Nusa Andalan, PT Multi Distribution Jaya Makmur and PT You You Glory Industry with more than 1 year of service. The data use for study were obtained through the questionnaires distributed online, in which to select respondents a purposive sampling method was applied. Then the collected data is processed with the analysis techniques of Structural Equation Modeling (SEM), using SmartPLS software. The results showed that job satisfaction did not affect organizational commitment. Meanwhile, organizational culture has a positive and significant influence on organizational commitment. The results of this study are expected to provide useful information for the problems that occur between job satisfaction and organizational culture on organizational commitment for employees of private companies in Tanjung Pandan, especially the 4 companies that have been studied, the private companies name is CV Mitra Sumber Mandiri, CV Laju Nusa Andalan, PT You You Glory Industry, and PT Multi Distribution Jaya Makmur.
\end{abstract}

Keywords: Job Satisfaction, Organizational Culture, Commitment Organizational.

Abstrak: Tujuan dari penelitian ini adalah untuk menguji pengaruh kepuasan kerja dan budaya organisasi terhadap komitmen organisasi karyawan. Responden dalam penelitian ini berjumlah 57 karyawan dari 4 perusahaan swasta di Tanjung Pandan yaitu CV Mitra Sumber Mandiri, CV Laju Nusa Andalan, PT Multi Distribusi Jaya Makmur dan PT You You Glory Industry dengan masa kerja lebih dari 1 tahun. Data didapat melalui penyebaran kuesioner secara online, di mana untuk mendapatkan responden diterapkan metode purposive sampling. Kemudian data tersebut diolah menggunakan teknik analisis Structural Equation Modeling (SEM), menggunakan software SmartPLS versi 3.3.3. Hasil penelitian menunjukkan kepuasan kerja tidak mempengaruhi komitmen organisasi. Sementara budaya organisasi memiliki pengaruh positif dan signifikan terhadap komitmen organisasi. Hasil penelitian ini diharapkan dapat memberikan informasi yang bermanfaat untuk permasalahan yang terjadi antara kepuasan kerja dan budaya organisasi terhadap komitmen organisasi bagi karyawan perusahaan swasta di Tanjung Pandan, khususnya empat perusahaan yang telah diteliti yaitu CV Mitra Sumber Mandiri, CV Laju Nusa Andalan, PT You You Glory Industry, dan PT Multi Distribusi Jaya Makmur.

Kata Kunci: Kepuasan Kerja, Budaya Organisasi, Komitmen Organisasi. 


\section{LATAR BELAKANG}

Sebelum abad ke-20, sumber daya manusia diposisikan sebagai mesin produksi yang mana digunakan ketika dapat mendatangkan laba bagi perusahaan. Memasuki abad ke-21 ini, manusia mulai kritis terhadap peranannya dalam sebuah organisasi hingga saat ini dapat dikatakan manusia menjadi faktor sentral bagi perusahaan yang mana dapat menghasilkan keuntungan dan membuat reputasi yang luar biasa bagi perusahaan.

Sumber daya manusia menjadi faktor penting dalam mendukung aktivitas dan kualitas sebuah organisasi dalam mencapai tujuan. Sumber daya manusia menjadi aset yang sangat berharga melebihi sumber daya lainnya seperti mesin, uang, material, metode, dan pasar (Sumual, 2017). Oleh karena itu, dapat dikatakan bahwa sehebat dan sebaik apapun perusahaan tidak akan berjalan dengan semestinya tanpa adanya sumber daya manusia didalamnya.

Secara umum, karyawan yang berkomitmen terhadap organisasi umumnya mempunyai hubungan yang baik dan merasa nyaman dengan organisasi serta memahami tujuan organisasi. Singh \& Onahring (2019) komitmen organisasi merupakan tingkat identifikasi, loyalitas, dan keterlibatan. Seseorang yang memiliki komitmen tinggi terhadap organisasi tidak mudah meninggalkan organisasi, ikut serta dalam keterlibatan, bahkan rela berkorban seperti memberikan waktu dan tenaga yang ekstra.

Karyawan akan berkomitmen terhadap organisasi apabila Ia memiliki kepuasan kerja dan merasa nyaman dengan nilai atau norma yang ditanamkan dalam perusahaan. Komitmen organisasi yang tinggi akan memberikan dampak nilai yang positif kepada organisasi. Namun, masih banyak perusahaan yang tidak memperhatikan komitmen karyawannya sehingga upaya mereka berikan terhadap pencapaian tujuan menjadi kurang maksimal.

Apabila karyawan memperoleh kepuasan kerja, ia akan menunjukkan komitmennya melalui sikap loyal terhadap perusahaan dan jika ketidakpuasan terjadi akan mengakibatkan secara mental dan emosional karyawan sering absen, datang tidak tepat waktu atau bahkan meninggalkan organisasi.

Faktor lain yang mempengaruhi komitmen organisasi karyawan ialah budaya organisasi. Singh \& Das (1978 dalam Nikpour, 2017) mengatakan budaya organisasi yang baik akan meningkatkan komitmen secara signifikan. Apabila karyawan merasa cocok dengan nilai atau norma perusahaan, mereka akan memiliki rasa komitmen terhadap organisasi dengan cara melibatkan serta mempertahankan keanggotaannya. Menurut Murat et al. (2014 dalam Cherif., 2020) karyawan yang tidak mempunyai komitmen terhadap organisasi atau tidak puas dengan pekerjaannya akan meningkatkan turnover. Organisasi tidak adanya komitmen akan berdampak terganggunya kondisi sumber daya manusia, produktivitas, serta lingkungan kerja yang tidak nyaman.

Bersumberkan penelitian yang telah dilakukan oleh Azeez et al. (2016) meneliti mengenai hubungan komitmen organisasi dengan kepuasan kerja dan turnover, dengan objek penelitian karyawan Lagos State University dan menyatakan bahwa kepuasan kerja dan turnover berpengaruh signifikan terhadap komitmen organisasi. Tidak jauh berbeda dengan penelitian selanjutnya oleh Inanlou \& Ahn (2017) yang meneliti komitmen organisasi sebagai variabel terikat yang dipengaruhi budaya organisasi, dengan subyek penelitian pengembangan sumber daya manusia di perusahaan Korea dan memberikan hasil bahwa budaya organisasi berpengaruh positif terhadap komitmen organisasi.

Merujuk pada hasil survei tersebut, peneliti tertarik untuk melakukan penelitian lebih lanjut mengenai seberapa pengaruh kepuasan kerja dan budaya organisasi terhadap komitmen organisasi karyawan perusahaan swasta di Tanjung Pandan. 


\section{KAJIAN TEORI}

\section{The Resource-Based View}

Teori Resource-Based View memandang bahwa faktor internal sumber daya dan keterampilan perusahaan menjadi sangat penting bagi organisasi dari pada faktor eksternal, karena sebagai dasar dari daya saing dan kinerja perusahaan. Teori RBV juga berasumsi tentang bagaimana suatu perusahaan dapat bersaing dengan perusahaan lainnya dengan cara mengatur sumber dayanya sesuai kemampuan yang dimiliki untuk mencapai dan mempertahankan keunggulan yang lebih tinggi dibandingkan perusahaan lain

\section{Komitmen Organisasi}

Kunci kesuksesan sebuah organisasi adalah tergantung pada komitmen dan keterlibatan karyawan. Komitmen organisasi merupakan kesediaan seorang karyawan untuk memberikan usaha yang maksimal bagi organisasi, keyakinan terhadap nilai dan tujuan organisasi serta tidak mempunyai keinginan untuk meninggalkan organisasi, maka komitmen organisasi memberikan pengaruh efektivitas organisasi Kaplan \& Kaplan (2018).

\section{Kepuasan Kerja}

Secara teoritis, seorang karyawan apabila merasakan kepuasan kerja maka akan memberikan prestasi kerja yang positif. Eliyana \& Ma'arif (2019) mengatakan organisasi yang memiliki karyawan yang puas akan bekerja secara efektif dan produktif. Judge \& Klinger (2008, dalam Choudhary \& Saini, 2021) mengatakan konsep kepuasan kerja adalah kepuasan subjektif di tempat kerja yang secara umum mengarah pada kepuasan individu pada pekerjaannya.

\section{Budaya Organisasi}

Budaya organisasi menjadi peran penting atas keberhasilan dan kegagalan sebuah organisasi dan dapat mempengaruhi komitmen organisasi pada seorang karyawan. Secara umum budaya organisasi merupakan lingkungan yang memiliki pengaruh terhadap cara mereka berpikir, bertindak, serta nilai dan keyakinan yang merupakan karakteristik organisasi tersebut Warrick (2017). Terdapat dua tipe budaya organisasi yakni dominant culture dan subculture. Dominant culture merupakan nilai inti dari perusahaan yang dianut oleh mayoritas anggota organisasi sehingga membedakan bentuk kepribadian antar organisasi, sedangkan subculture merupakan lahirnya nilai dalam organisasi berdasarkan ruang lingkup karyawan atau departemen masing-masing Stanley \& Ie (2019).

\section{Kaitan antara Kepuasan Kerja terhadap Komitmen Organisasi}

Kepuasan kerja merupakan kondisi emosional yang menyenangkan yang dimiliki seorang karyawan terhadap pekerjaannya Thiagaraj \& Thangaswamy (2017). Apabila seorang karyawan merasa puas terhadap pekerjaannya cenderung untuk mempertahankan keberadaannya di dalam organisasi maka, memberikan pengaruh yang positif terhadap komitmen organisasi Malik et al. (2010, dalam Saridakis et al, 2020).

Berdasarkan penelitian Yanti \& Dahlan (2017) terdapat hasil kepuasan kerja berpengaruh positif terhadap komitmen organisasi. Artinya apabila aspek pekerjaan diterima baik oleh karyawan maka karyawan akan didorong untuk berkomitmen dengan demikian diharapkan kepuasan kerja memiliki pengaruh secara langsung terhadap komitmen organisasi. Tidak berbeda dengan penelitian yang dilakukan oleh Azeez et al. (2016) 
mendapatkan hasil bahwa kepuasan kerja berpengaruh signifikan terhadap komitmen organisasi.

\section{Kaitan antara Budaya Organisasi terhadap Komitmen Organisasi}

Budaya organisasi adalah alat dasar untuk menciptakan komitmen organisasi, semakin baik nilai dan persepsi yang ditanamkan maka akan terciptanya komitmen organisasi yang lebih baik. nilai dan kepercayaan yang ada dalam organisasi sebagai referensi tindakan serta yang membedakan antara organisasi lainnya Brewer \& Clippard (2002, dalam Aranki et al., 2019). Apabila budaya organisasi dapat diterima oleh karyawan maka akan meningkatkan keterlibatannya dalam organisasi serta keinginan untuk tetap berada didalam organisasi dan hal tersebut meningkatkan komitmen organisasi.

Penelitian yang dilakukan oleh Yaseen et al. (2018) menemukan hasil budaya organisasi memiliki pengaruh positif dan signifikan terhadap komitmen organisasi. Hasil yang sama juga didapatkan berdasarkan penelitian Ellys \& Ie (2020) menunjukkan budaya organisasi berpengaruh positif terhadap komitmen organisasi karyawan. Artinya bahwa budaya organisasi memiliki peranan yang penting dalam menciptakan serta meningkatkan komitmen organisasi.

\section{Hipotesis}

Komitmen organisasi merupakan salah satu faktor penting untuk mencapai tujuan organisasi. Seorang karyawan yang memiliki komitmen terhadap organisasinya akan bekerja dengan memberikan waktu, pikiran, tenaga secara maksimal oleh karena itu, harapan organisasi akan dengan mudah tercapai. Contoh komitmen organisasi adalah keterlibatan dan loyalitas seorang karyawan pada organisasi.

Komitmen organisasi dipengaruhi oleh beberapa faktor seperti kepuasan kerja. Kepuasan kerja merupakan perasaan senang atau puas seorang karyawan terhadap pekerjaannya. Karyawan akan mendapatkan kepuasan pada pekerjaannya apabila aspek pekerjaan seperti upah, promosi, sifat pekerjaan itu sendiri, hubungan antar rekan kerja dapat diterima secara baik.

Selain kepuasan kerja, faktor yang mempengaruhi komitmen organisasi adalah budaya organisasi. Budaya organisasi merupakan nilai, norma, kepercayaan yang ada didalam organisasi yang menjadi dasar seorang karyawan berperilaku dalam bekerja. Apabila budaya organisasi yang terdapat di suatu perusahaan seperti nilai, kepercayaan, gaya kepemimpinan, bagaimana seseorang diperlakukan dianggap sesuai dengan gaya kerjanya maka, karyawan akan berkomitmen untuk tetap mempertahankan keberadaannya dalam suatu perusahaan.

Dari uraian diatas mengenai hal-hal yang mempengaruhi komitmen organisasi maka, terbentuklah model penelitian sebagai berikut. 


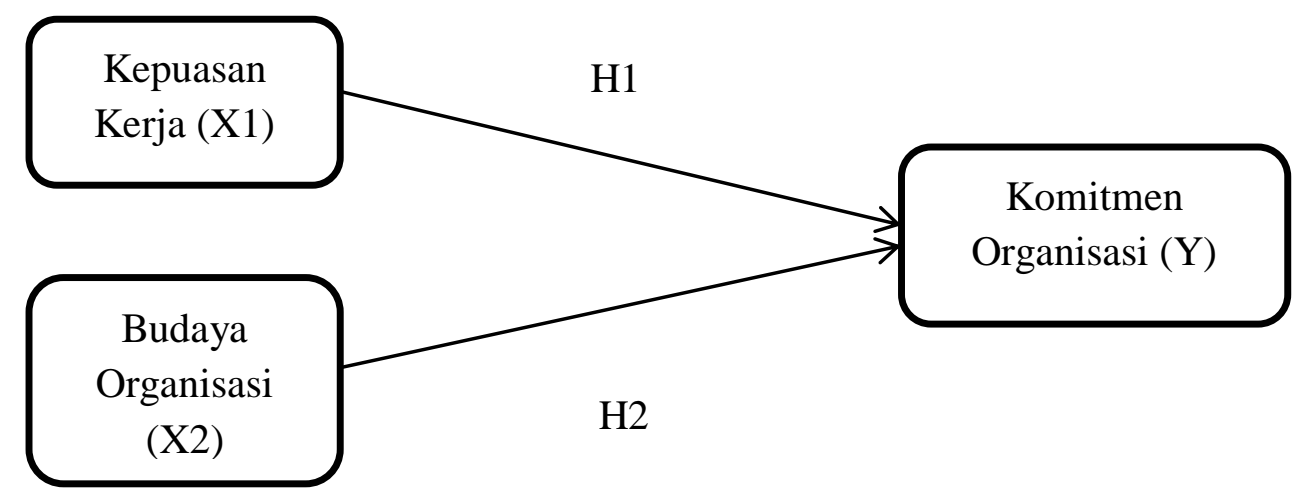

\section{Gambar 1 \\ Model Penelitian}

Hipotesis dalam penelitian ini dapat dirumuskan sebagai berikut:

H1: Kepuasan kerja berpengaruh positif dan signifikan terhadap komitmen organisasi karyawan.

$\mathrm{H} 2$ : Budaya organisasi berpengaruh positif dan signifikan terhadap komitmen organisasi karyawan.

\section{METODOLOGI}

Berdasarkan tujuannya, penelitian ini dapat dikategorikan sebagai penelitian eksplanatif, dengan menggunakan pendekatan kuantitatif. Penelitian ini menggunakan data primer yang dikumpulkan melalui metode survei, dengan menyebarkan kuesioner dalam bentuk Google form secara online. Populasi penelitian ini terdiri dari berjumlah 73 karyawan perusahaan swasta di Tanjung Pandan dengan penjabaran sebagai berikut: CV Mitra Sumber Mandiri yang terdiri dari 12 karyawan, CV Laju Nusa Andalan yang terdiri dari 15 karyawan, PT You You Glory Industry yang terdiri dari 5 karyawan dan PT Multi Distribusi Jaya Makmur yang terdiri dari 40 karyawan. Teknik pengambilan sampel yang diterapkan adalah non probability sampling, yakni secara purposive sampling. Data primer yang telah terkumpul selanjutnya akan dianalisis dengan teknik analisis Structural Equation Modeling (SEM), dan diolah dengan bantuan software SmartPLS versi 3.3.3. Di mana SmartPLS digunakan untuk menguji hubungan, pengaruh, dan kelayakan instrumen penelitian. Analisis data dalam penelitian ini terdiri dari pengujian model pengukuran (uji validitas dan reliabilitas), uji model struktural (uji coefficient of determination, uji predictive relevance, dan uji effect size), uji Goodness of Fit (GoF), dan uji hipotesis (path coefficient, t-statistic, dan p-value).

\section{HASIL ANALISIS DATA}

Diperoleh sebanyak 57 sampel yang memenuhi kriteria untuk penelitian ini. Selanjutnya data tersebut di uji validitas (Convergent Validity dan Discriminant Validity) dan reliabilitasnya untuk memastikan kualitas dari data responden. 
Tabel 1

Hasil Uji Average Variance Extracted (Convergent Validity)

\begin{tabular}{|l|c|}
\hline & AVE \\
\hline Kepuasan Kerja (X1) & 0,561 \\
\hline Budaya Organisasi (X2) & 0,685 \\
\hline Komitmen Organisasi (Y) & 0,636 \\
\hline
\end{tabular}

Sumber: Hasil olahan peneliti menggunakan SmartPLS versi 3.3.3

Dari tabel 1 dapat dilihat bahwa setiap indikator pada penelitian ini dinyatakan valid, karena nilai AVE di setiap variabel yaitu variabel kepuasan kerja, budaya organisasi, dan komitmen organisasi lebih besar dari 0,5. Indikator dinyatakan valid ketika nilai AVE menunjukkan sama dengan $0.5(=0.5)$ atau lebih besar dari 0.5 atau (>0.5) Hair et al. (2020).

\section{Tabel 2}

Hasil Uji Cross Loading (Discriminant Validity)

\begin{tabular}{|c|c|c|c|}
\hline & $\begin{array}{c}\text { Kepuasan Kerja } \\
\text { (X1) }\end{array}$ & $\begin{array}{c}\text { Budaya Organisasi } \\
(\mathrm{X} 2)\end{array}$ & $\begin{array}{c}\text { Komitmen Organisasi } \\
\text { (Y) }\end{array}$ \\
\hline KK1 & 0,666 & 0,354 & 0,399 \\
\hline KK2 & 0,506 & 0,364 & 0,307 \\
\hline KK3 & 0,736 & 0,344 & 0,233 \\
\hline KK4 & $\mathbf{0 , 8 2 0}$ & 0,493 & 0,294 \\
\hline KK5 & $\mathbf{0 , 8 3 8}$ & 0,537 & 0,522 \\
\hline KK6 & 0,865 & 0,628 & 0,524 \\
\hline KK7 & $\mathbf{0 , 8 3 7}$ & 0,519 & 0,404 \\
\hline KK8 & 0,816 & 0,616 & 0,498 \\
\hline KK9 & 0,743 & 0,442 & 0,283 \\
\hline KK10 & 0,573 & 0,263 & 0,064 \\
\hline BO1 & 0,624 & 0,784 & 0,563 \\
\hline $\mathrm{BO} 2$ & 0,552 & $\mathbf{0 , 8 3 4}$ & 0,543 \\
\hline BO3 & 0,545 & $\mathbf{0 , 8 9 8}$ & 0,509 \\
\hline $\mathrm{BO} 4$ & 0,371 & $\mathbf{0 , 7 8 3}$ & 0,549 \\
\hline BO5 & 0,525 & 0,894 & 0,711 \\
\hline BO6 & 0,593 & 0,763 & 0,469 \\
\hline KO1 & 0,534 & 0,709 & 0,890 \\
\hline
\end{tabular}


Suyanto dan Ie: Pengaruh Kepuasan Kerja Dan Budaya Organisasi...

\begin{tabular}{|c|c|c|c|}
\hline KO2 & 0,472 & 0,600 & $\mathbf{0 , 8 4 0}$ \\
\hline KO3 & 0,366 & 0,454 & $\mathbf{0 , 7 6 9}$ \\
\hline KO5 & 0,416 & 0,541 & $\mathbf{0 , 8 5 8}$ \\
\hline KO6 & 0,244 & 0,319 & $\mathbf{0 , 5 9 8}$ \\
\hline
\end{tabular}

Sumber: Hasil olahan peneliti menggunakan SmartPLS versi 3.3.3

Dari tabel 2 tentang uji cross loading, dapat dikatakan bahwa masing-masing dari indikator pada variabel penelitian ini menunjukkan nilai valid, karena nilai cross loading di setiap konstruk memiliki nilai lebih besar dari konstruk lainnya. Cross loading digunakan untuk mengukur validitas diskriminan, yang mana cross loading pada indikator pada konstruk tersebut harus lebih besar dari pada nilai variabel lainnya Wong (2016).

Tabel 3

Hasil Uji Reliabilitas

\begin{tabular}{|c|c|c|}
\hline & Cronbach's Alpha & Composite Reliability \\
\hline $\begin{array}{c}\text { Kepuasan Kerja } \\
\text { (X1) }\end{array}$ & 0,913 & 0,926 \\
\hline $\begin{array}{c}\text { Budaya } \\
\text { Organisasi (X2) }\end{array}$ & 0,907 & 0,929 \\
\hline $\begin{array}{c}\text { Komitmen Organisasi } \\
\text { (Y) }\end{array}$ & 0,855 & 0,896 \\
\hline
\end{tabular}

Sumber: Hasil olahan peneliti menggunakan SmartPLS versi 3.3.3

Dari tabel 3 dilihat nilai cronbach's alpha dan composite reliability menunjukkan nilai dari tiap-tiap variabel lebih dari 0,7 maka indikator dianggap reliabel. Suatu instrumen dikatakan reliabel apabila nilai Cronbach's Alpha dan Composite Reliability menunjukkan nilai lebih dari 0.7 (>0.7) Sani \& Wiliani (2019).

Setelah uji validitas dan uji reliabilitas yang merupakan pengujian model pengukuran, selanjutnya dilakukan uji model struktural struktural (uji coefficient of determination, uji predictive relevance, dan uji effect size), uji Goodness of Fit, dan uji hipotesis (path coefficient, t-statistic, dan p-value).

Tabel 4

\section{Hasil Uji Coefficient of Determination dan Predictive Relevance}

\begin{tabular}{|c|c|c|}
\hline & $\mathbf{R}^{\mathbf{2}}$ & $\mathbf{Q}^{\mathbf{2}}$ \\
\hline Komitmen Organisasi & 0,482 & 0,275 \\
\hline
\end{tabular}

Sumber: Hasil olahan peneliti menggunakan SmartPLS versi 3.3.3

Uji koefisien determinasi berguna untuk mengetahui seberapa besar kontribusi variabel bebas terhadap variabel terikat yang ada di dalam penelitian. Dari tabel 4 diketahui bahwa nilai $\mathrm{R}^{2}$ sebesar 0,482 , yang artinya variabel komitmen organisasi dapat dijelaskan oleh variabel kepuasan kerja dan budaya organisasi sebesar 48,2\% dan sisanya sebesar 51,8\% 
dapat dijelaskan oleh variabel lain di luar penelitian ini. Kemudian berdasarkan klasifikasi nilai $\mathrm{R}^{2}$ menurut Hair et al., (2013, dalam Wong, 2016). yaitu $\mathrm{R}^{2}$ dikelompokkan menjadi lemah $(0,25)$, sedang $(0,5)$, dan kuat $(0,7)$, maka dapat disimpulkan bahwa penelitian ini termasuk lemah karena nilainya di bawah 0,5 .

Predictive relevance digunakan untuk menguji bagaimana nilai observasi yang merupakan hasil dari bagian model Khairunnisa et al. (2020). Diperoleh nilai $\mathrm{Q}^{2}$ dari variabel intensi penggunaan adalah 0,275 , dimana lebih besar daripada 0 . Sehingga model penelitian dianggap predictive relevance, yang artinya kepuasan kerja dan budaya organisasi (selaku variabel eksogen) dapat digunakan untuk memprediksi komitmen organisasi (selaku variabel endogen) dengan baik.

Tabel 5

Hasil Uji Effect Size

\begin{tabular}{|c|c|}
\hline & $\mathbf{F}^{2}$ \\
\hline Kepuasan Kerja & 0,026 \\
\hline Budaya Organisasi & 0,390 \\
\hline
\end{tabular}

Berlandaskan tabel 5, dapat diketahui bahwa nilai $\mathrm{F}^{2}$ dari kepuasan kerja memiliki nilai sebesar 0,026, yang artinya kepuasan kerja memiliki efek lemah terhadap komitmen organisasi; nilai $\mathrm{F}^{2}$ dari budaya organisasi memiliki nilai sebesar 0,390 , yang artinya budaya organisasi memiliki efek kuat terhadap komitmen organisasi.

$$
\mathrm{GoF}=\sqrt{0,627 \times 0,482}=0,549
$$

Berdasarkan hasil di atas yang dihitung manual, dapat disimpulkan bahwa model penelitian ini mempunyai kesesuaian yang dikategorikan besar, karena nilai GoF 0,549 $\geq$ 0,36 .

Tabel 6

Hasil Uji Hipotesis path coefficients, t-statistic, dan p-value

\begin{tabular}{|l|c|c|c|}
\hline & $\begin{array}{c}\text { Path } \\
\text { Cofficients }\end{array}$ & T-Statistic & P-Value \\
\hline Kepuasan Kerja => Komitmen Organisasi & 0,151 & 1,505 & 0,133 \\
\hline $\begin{array}{l}\text { Budaya Organisasi => Komitmen } \\
\text { Organisasi }\end{array}$ & 0,587 & 5,718 & 0,000 \\
\hline
\end{tabular}

Sumber: Hasil olahan peneliti menggunakan SmartPLS versi 3.3.3

Untuk menentukan hipotesis yang dibuat peneliti diterima, ditolak, dan signifikan dapat dilihat uji path coefficient, $t$-statistic, serta signifikansi (p-value) antar variabel.

Berdasarkan tabel 6 dapat dilihat bahwa nilai path coefficients dari kepuasan kerja terhadap komitmen organisasi menunjukkan nilai 0,151 , yang berarti kepuasan kerja memiliki pengaruh yang lemah dan arah yang positif terhadap komitmen organisasi.

Kemudian, kepuasan kerja terhadap komitmen organisasi terdapat nilai t-statistic sebesar 1,505 yang mana menunjukkan angka lebih kecil dari 1,96 dengan p-value senilai 0,133 artinya lebih besar dari 0,05 .

Maka dapat disimpulkan bahwa H1 ditolak karena tidak memenuhi syarat untuk diterimanaya suatu hipotesis yang mana nilai t-statistic $<1,96$ dan p-value $>0,05$. Hal tersebut dapat diartikan bahwa kepuasan kerja memiliki pengaruh positif namun tidak signifikan terhadap komitmen organisasi. 
Nilai path coefficients dari budaya organisasi terhadap komitmen organisasi menunjukkan nilai 0,587, yang dapat diartikan budaya organisasi memiliki hubungan yang kuat dan arah yang positif terhadap komitmen organisasi. Variabel budaya organisasi memiliki pengaruh yang terbesar dalam penelitian ini.

Budaya organisasi terhadap komitmen organisasi mempunyai nilai t-statistic sebesar 5,718, artinya lebih besar dari 1,96 dengan p-value sebesar 0,000 di mana nilai tersebut lebih kecil dari 0,05 .

Oleh karena itu, peneliti menyimpulkan bahwa $\mathrm{H}^{2}$ diterima karena memenuhi syarat untuk diterimanya suatu hipotesis yang mana t-statistic $>1,96$ dan p-value $<0,05$. Hal tersebut berarti budaya organisasi memiliki pengaruh positif dan signifikan terhadap komitmen organisasi.

\section{Diskusi dan Pembahasan}

\section{Pengaruh Kepuasan Kerja terhadap Komitmen Organisasi}

Hasil pengujian hipotesis pertama pada penelitian ini menunjukkan bahwa kepuasan kerja berpengaruh positif dan tidak signifikan terhadap komitmen organisasi karyawan perusahaan swasta di Tanjung Pandan. Indikator kepuasan kerja yang paling berpengaruh terhadap komitmen organisasi ialah memiliki rekan kerja yang bertanggung jawab dalam melaksanakan tugasnya. Pernyataan tersebut disertai dengan alasan karena para karyawan merasa mempunyai rekan kerja yang bertanggung jawab dalam melaksanakan tugasnya. Tindakan yang bertanggung jawab misalnya menyelesaikan tugas pekerjaan tidak melewati tanggal deadline. Sehingga, sesama rekan kerja merasa senang ketika melihat teman kerjanya melaksanakan tugas dengan baik dan bisa sebagai motivasi untuk teman-teman lainnya.

Hasil penelitian ini tidak serupa dengan studi yang dilakukan oleh (Yanti \& Dahlan, 2017; Babalola, 2016). Studi tersebut mendapatkan hasil kepuasan kerja memiliki pengaruh signifikan terhadap komitmen organisasi yang dilakukan penelitian kepada karyawan di unit teknis pelaksana Dinas Pendidikan Kab. Tangerang dan karyawan Oyo di Nigeria. Hal ini dapat diartikan bahwa kepuasan kerja memiliki pengaruh terhadap komitmen organisasi hanya berlaku di beberapa tempat penelitian saja seperti pada karyawan teknis Dinas Pendidikan Kab. Tangerang dan karyawan Oyo di Nigeria, mungkin karyawan tersebut memiliki kepuasan kerja yang baik terhadap organisasi seperti memiliki emosional yang positif terhadap pekerjaannya saat ini, sehingga dengan memiliki kepuasan kerja saja dapat membuat karyawan tersebut berkomitmen terhadap organisasi dengan mempertahankan keberadaannya dalam organisasi. Tetapi kedua penelitian tersebut tidak berlaku pada karyawan perusahaan swasta di Tanjung Pandan.

\section{Pengaruh Budaya Organisasi Terhadap Komitmen Organisasi}

Hasil uji hipotesis kedua dalam penelitian ini menunjukkan hasil bahwa budaya organisasi memiliki pengaruh positif dan signifikan terhadap komitmen organisasi. Hal tersebut didukung oleh indikator budaya organisasi yang paling mempengaruhi komitmen organisasi ialah perusahaan mendorong perlunya perubahan dan inovasi. Alasannya karena karyawan merasa berada pada perusahaan yang mendorong untuk berinovasi bagi kinerjanya maupun keberlangsungan organisasi.

Hasil penelitian ini sejalan dengan analisis yang dilakukan oleh Kawiana et al. (2018) dan Yaseen et al. (2018) Temuan menunjukkan bahwa budaya organisasi berpengaruh positif terhadap komitmen organisasi pada karyawan Bank Perkreditan Rakyat (BPR) di Bali dan dosen perguruan tinggi Pakistan. Artinya dapat disimpulkan bahwa apabila karyawan merasa nyaman dan cocok pada sebuah organisasi yang terdapat budaya yang kuat seperti 
menanamkan nilai dan norma yang baik, maka karyawan akan memiliki komitmen untuk tetap terlibat dalam organisasi.

\section{KESIMPULAN}

Berdasarkan hasil penelitian, maka saran yang diberikan adalah:

1. Penelitian ini mendapatkan hasil bahwa kepuasan kerja tidak berpengaruh terhadap komitmen organisasi sedangkan budaya organisasi memiliki pengaruh positif dan signifikan terhadap komitmen organisasi, ini menandakan bahwa meskipun budaya organisasi yang telah tertanam pada sebuah perusahaan cocok dengan cara kerjanya karyawan, tidak menutup kemungkinan bahwa keinginan karyawan untuk tetap berada dalam organisasi masih minim. Oleh karena itu, peneliti menyarankan agar human resource development untuk tetap fokus dengan kepuasan kerja karyawan sehingga tercapainya tujuan perusahaan dalam meningkatkan komitmen karyawan terhadap organisasi. Contoh sikap komitmen terhadap organisasi yang dilakukan karyawan yaitu dengan bersikap loyal pada perusahaan. Apabila, karyawan bersikap loyal akan berpengaruh pada produktivitas perusahaan sehingga, perusahaan akan dengan mudah mencapai target yang telah ditentukan.

2. Supaya penelitian lebih berkembang, maka disarankan pada penelitian selanjutnya agar melibatkan variabel-variabel lain yang memiliki pengaruh terhadap komitmen organisasi. Karena nilai $\mathrm{R}^{2}$ pada penelitian ini sebesar $48,2 \%$, sehingga tersisa $51,8 \%$ yang bisa dijelaskan dengan variabel-variabel lain yang tidak diteliti dalam penelitian ini.

3. Peneliti juga menyarankan penelitian selanjutnya agar dapat memperluas wilayah atau jangkauan sampel, sehingga hasil penelitian lebih mencerminkan karakteristik populasi maupun kondisi yang sebenarnya dan juga melibatkan variabel-variabel lain yang memiliki pengaruh terhadap komitmen organisasi.

\section{DAFTAR PUSTAKA}

Aranki, D., Suifan, T., \& Sweis, R. (2019). The relationship between organizational culture and organizational commitment. Modern Applied Science, 13(4), 137-154.

Azeez, R. O., Jayeoba, F., \& Adeoye, A. O. (2016). Job satisfaction, turnover intention and organizational commitment. Journal of Management Research, 8(2), 102-114.

Babalola, S. S. (2016). The effect of leadership style, job satisfaction and employeesupervisor relationship on job performance and organizational commitment. Journal of Applied Business Research (JABR), 32(3), 935-946.

Cherif, F. (2020). The role of human resource management practices and employee job satisfaction in predicting organizational commitment in Saudi Arabian banking sector. International Journal of Sociology and Social Policy. 40(7/8), 529-541.

Choudhary, V., \& Saini, G. (2021). Effect of job satisfaction on moonlighting intentions: Mediating effect of organizational commitment. European Research on Management and Business Economics, 27(1), 100137.

Eliyana, A., \& Ma'arif, S. (2019). Job satisfaction and organizational commitment effect in the transformational leadership towards employee performance. European Research on Management and Business Economics, 25(3), 144-150. 
Ellys, E., \& Ie, M. (2020). Pengaruh kepuasan kerja dan budaya organisasi terhadap komitmen organisasi karyawan. Jurnal Manajemen Maranatha, 20(1), 75-84.

Hair, J. F., Howard, M. C., \& Nitzl, C. (2020). Assessing measurement model quality in PLSSEM using confirmatory composite analysis. Journal of Business Research, 109, 101110.

Inanlou, Z., \& Ahn, J. Y. (2017). The effect of organizational culture on employee commitment: A mediating role of human resource development in Korean firms. Journal of Applied Business Research (JABR), 33(1), 87-94.

Kaplan, M., \& Kaplan, A. (2018). The relationship between organizational commitment and work performance: A case of industrial enterprises. Journal of Economic and Social Development (JESD), 5(1), 46-50.

Kawiana, I. G. P., Dewi, L. K. C., Martini, L. K. B., \& Suardana, I. B. R. (2018). The influence of organizational culture, employee satisfaction, personality, and organizational commitment towards employee performance. International Research Journal of Management, IT and Social Sciences, 5(3), 35- 45.

Khairunnisa, A. H., Ningrum, J. W., Huda, N., \& Rini, N. (2020). Pengaruh brand awareness dan kepercayaan terhadap keputusan menyalurkan zakat dan donasi melalui Tokopedia. Jurnal Ilmiah Ekonomi Islam, 6(2), 284-293.

Nikpour, A. (2017). The impact of organizational culture on organizational performance: The mediating role of employee's organizational commitment. International Journal of Organizational Leadership, 6, 6572.

Sani, A., \& Wiliani, N. (2019). Faktor kesiapan dan adopsi teknologi informasi dalam konteks teknologi serta lingkungan pada UMKM di Jakarta. JITK (Jurnal Ilmu Pengetahuan Dan Teknologi Komputer), 5(1), 49-56.

Saridakis, G., Lai, Y., Muñoz Torres, R. I., \& Gourlay, S. (2020). Exploring the relationship between job satisfaction and organizational commitment: an instrumental variable approach. The International Journal of Human Resource Management, 31(13), 17391769.

Singh, K. D., \& Onahring, B. D. (2019). Entrepreneurial intention, job satisfaction and organisation commitment-construct of a research model through literature review. Journal of Global Entrepreneurship Research, 9(1), 1-18.

Stanley., \& Ie, M. (2019). Pengaruh Budaya Organisasi Dan Lingkungan Kerja Terhadap Kepuasan Kerja Di PT. XYZ Di Jakarta. Jurnal Manajerial Dan Kewirausahaan, 1(3), 578-584.

Sumual, T. E. M. (2017). Manajemen sumber daya manusia. Edisi revisi. Surabaya: $\quad$ CV. R.A.De. Rozarie.

Thiagaraj, D., \& Thangaswamy, A. (2017). Theoretical concept of job satisfaction-a study. International Journal of Research-Granthaalayah, 5(6), 464-470.

Warrick, D. D. (2017). What leaders need to know about organizational culture. Business Horizons, 60(3), 395-404.

Wong, K. K. K. (2016). Mediation analysis, categorical moderation analysis, and higherorder constructs modeling in Partial Least Squares Structural Equation Modeling (PLS-SEM): A B2B Example using SmartPLS. Marketing Bulletin, 26, 1-22.

Yanti, S., \& Dahlan, J. A. (2017). The effects of organizational culture, leadership behavior, and job satisfaction on employee organizational commitment. Journal of Positive Management, 8(4), 80-96. 
Yaseen, S., Ali, H. Y., \& Asrar-ul-Haq, M. (2018). Impact of organizational culture and leadership style on employee commitment towards change in higher education institutions of Pakistan. Paradigms, 12(1), 44-53. 